\title{
The Civilian Cyber InCident Response POLICIES OF THE U.S. Federal Government
}

CHRIS BRONK

\section{Contents}

Introduction 256

The Cyber Incident Conundrum 257

Civilian Response Policies 258

The Policy Umbrella: The Federal Information Security

Management Act (FISMA) 259

Managing Incidents: Guidance from Government 261

Step 1: Preparation $\quad 262$

Step 2: Detection and Analysis 262

Step 3: Containment, Eradication, and Recovery 263

Step 4: Postincident Activity 263

U.S. Computer Emergency Readiness Team (US-CERT) 263

Constructing National Policy for Cyber Incident Response 264

Currently Planned Efforts 265

Concept of Operations $\quad 267$

The Response Center 268

The Response Cycle $\quad 269$

Roles and Responsibilities $\quad 270$

Ways Forward 270

References $\quad 272$ 


\section{Introduction}

Cyber, in certain circles one does not even need to append "security" to the term, is a topic of burgeoning interest for several reasons. First, ubiquitous and mobile computing coupled with the movement toward digital formats and the low cost of reproduction has resulted in government fear for loss of information control. This is a problem both in regard to personally identifiable information (PII) of public sector employees and those served by them as well as confidentiality of records not meant for public consumption, exemplified by the intelligence reports posted by WikiLeaks. Second, information technology (IT) has changed the way government works and has become a massive component of public sector budgets. According to the Federal IT Dashboard, the federal government spent $\$ 81.9$ billion on IT in fiscal year 2010. Third, securing information systems is costly. According to the Office of Management and Budget (OMB), the Department of Homeland Security holds a 2011 budget of more than $\$ 350$ million for its cybersecurity directorate while the National Security Agency spends upwards of $\$ 1$ billion on securing the systems of the Department of Defense (DoD) alone, according to the 2011 budget request and reports in Information Week (Hoover, 2010), an industry publication. As funding increases, the cybersecurity agenda in Washington will continue to rise in political importance.

But despite all this spending, government computer systems remain vulnerable. For example, three-quarters (75\%) of 217 seniorlevel IT executives at U.S. federal organizations said they experienced one or more data breach incidents in the prior year, according to a 2009 survey conducted by the Ponemon Institute, a consultancy. How to respond to such cyber incidents, whether major data breaches or potentially crippling attacks launched against pieces of critical infrastructure, such as the power grid or telecommunications system, is a major challenge. The global digital interconnection and reliance on networked computers will lead to unanticipated externalities, prompting serious thought about the current state of cyber incident response for government organizations. Two major events in 2010 illustrate this new security era. First, to the dismay of officials around the world, WikiLeaks, an online nonprofit organization, demonstrated the potential unintended consequences of massive digital 
information compromise by posting thousands of U.S. government reporting cables and raw intelligence reports on the Internet for anyone to view. Second, the reported execution of Stuxnet, a malicious computer worm targeting an Iranian uranium enrichment facility at Natanz, exemplified that it is possible to accomplish physical damage using the Internet.

In order to help public sector managers gain a better operational understanding of their cyber environment, the first part of this chapter provides an overview of the civilian U.S. federal government cyber incident response challenges and reviews relevant policies, including requirements of the Federal Information Security Management Act (FISMA) and guidance from the National Institute for Standards and Technology (NIST) and other civilian agencies. The second part discusses the issue of a national cyber incident response policy, with emphasis on the draft National Cyber Incident Response Plan (NCIRP) and the issues present in mounting an effective response to the sorts of events within the domain of possibility, both known and unknown.

\section{The Cyber Incident Conundrum}

A cyber attack will generally render three possible results: (1) a denial of availability to information, (2) a compromise of confidentiality of information, or (3) a subversion of the integrity of information. Denial of availability may be undertaken to protest a particular policy or government service. Thieves may profit from confidential information. Altering government documents may sow confusion or obstruct lawful activity. Typically, we would see these as criminal acts. And there is general agreement that cybercrime is a growing problem. However, differentiating between criminal acts, mere electronic hooliganism, or serious threats to national security is not always apparent as a cyber attack is detected or unfolds.

In coping with cybersecurity, public sector managers must connect government policy with the technical vocabulary of computing and information security. In any real-world incident scenario, the primary issue for the information manager is simply to make the unauthorized activity stop. This necessitates asking what policy has been enacted to aid systems managers in achieving this. Mitigation is at the heart 
of any incident response and has been incorporated into the policy directives adopted by the U.S. government in the last decade, but less is known of the response process.

Responding to cyber incidents is a dynamic activity as they vary tremendously in impact and scope. For example, some incidents can be seen immediately, such as when systems are knocked offline, but for others this may not be the case, as breaches can continue for periods of great length without discovery. For the IT manager, whether a systems administrator, division head, or chief information officer (CIO), the issue of how to respond should cover a number of questions:

- Is the incident ongoing or has activity ceased?

- Have the culpable parties and technologies been located?

- Should notice of the incident, as currently understood, be passed to higher authority?

- Should vendors of affected technologies or those providing other services be contacted?

- Is it necessary to report the incident to law enforcement?

- Does the incident indicate a wider pattern of activity?

Although this list of considerations is by no means exhaustive, it represents the sort of thinking embodied in the organizational triage that is and will continue to be required in responding to incidents in which digital resources are compromised. Mitigation of incidents increasingly involves elements beyond technology. This provides an important insight for incident response: prevention is often painfully simple in hindsight. For example, according to the 2010 Data Breach Investigations Report from Verizon, an American telecommunications firm, $85 \%$ of confirmed data breaches were not deemed highly difficult and $96 \%$ of them could have been avoided through simple or intermediate controls.

\section{Civilian Response Policies}

Early manifestation of government's desire to secure digital resources can be traced to research by organizations such as SRI International and MITRE by Bell and LaPadula (1973) on behalf of the Department of Defense on computer security, which eventually grew into policy through publication of the Trusted Computer 
Security Evaluation Criteria (TCSEC), which dates to 1983. These works largely focused on how to protect information resources through system design. This remains a point of emphasis for computer security, as policy guidance still largely covers prevention of incidents rather than a response to them.

At a time when former generals and top-level government officials, such as William Lynn (2010), the Deputy Secretary of Defense, warn of potentially massive disruptions to critical infrastructures, such as power and water provision, the U.S. government appears woefully behind in securing its own computer systems as well as those it depends upon, which are held by other public and private stakeholders. But arguments that federal systems are either hopelessly vulnerable or amply protected are both flawed. With a middle ground somewhere between those poles as our starting point, reevaluating strategy of response to improve incident management is required. This is largely because existing policy has not been linked to any improvement in either vulnerability mitigation or enhanced incident response capabilities. The information security strategy for the classified systems of the military and intelligence services will largely take place out of public view and is not considered in the purview of this chapter. Thus, high-level policy consideration is largely directed at the Federal Information Security Management Act (FISMA) of 2002 that dictates security policy for unclassified information systems.

\section{The Policy Umbrella: The Federal Information Security Management Act (FISMA)}

In 2002, FISMA instituted government-wide directions for federal agencies to secure their information systems. It mandated that agencies would send reports to the Office of Management and Budget (OMB) and then receive feedback regarding performance. The process, grossly simplified, involves (1) creating an inventory of systems, (2) categorizing information on the systems and determining its importance, (3) conducting risk assessment, (4) creating a security plan, (5) certifying and accrediting systems, and (6) engaging in continuous monitoring of systems. With FISMA, OMB, in theory, could 
deny an agency funding if it failed to take adequate measures to secure its computer systems.

But FISMA did not solve the government's information security problems. To an outside observer, such as security specialist $\mathrm{Wm}$. Arthur Conklin (2008), it seems that much or even most federal activity on the security of information systems emphasizes preparedness and an understanding of systems operations rather than proper incident response. FISMA put the task of implementing the law's provisions upon the agencies themselves, with OMB standing as a reviewer of reporting. A recurring question of those responsible for information systems security in government agencies was what bearing the paperwork process of FISMA, primarily the ongoing need to certify and accredit systems as secure, had on the actual information security posture of those systems.

To a computer engineer or systems administrator focusing on the security of systems, the idea that an annual review or multiyear certification would say much of anything about systems security is incomprehensible as threats continuously evolve. A properly certified system may become vulnerable at any time. Accreditation does not provide a guarantee of trouble-free operation but rather offers a basic level of certainty that the system is operating in a manner that security practitioners would find acceptable.

Despite this, federal agencies' systems security offices and the firms they contract to produce the reporting to comply with the law expend considerable effort in filling out certification and accreditation (C\&A) reporting templates as a part of the FISMA process. In 2010, there has been increased push back on how to meet the FISMA mandate. In May, NASA's deputy CIO for IT security, Jerry Davis, argued in an agency-wide memorandum that the fiscal year 2010 FISMA instructions from OMB were, "clear regarding a shift away from cumbersome and expensive C\&A paperwork processes, in favor of a value-driven, risk-based approach to systems security" (p. 1). What is unclear, however, is exactly how such an approach to cybersecurity would be undertaken. There may be a consensus that the certification and accreditation machine that FISMA has become is undesirable or even perhaps counterproductive, but the alternatives are unknown. 


\section{Managing Incidents: Guidance from Government}

Moving beneath the umbrella that FISMA represents, the U.S. government has also produced significant guidance on how to prepare for information security incidents. The National Institute for Standards and Technology (NIST) within the Department of Commerce is tasked with translating the vision encapsulated within FISMA into binding standards called the Federal Information Processing Standards (FIPS) and recommendations (Special Publications). In a role defined by the OMB's Circular A-130, NIST standards and guidance produced by its Computer Security Division are applied to all federal information systems transmitting unclassified information (see Table 10.1). There are currently 14 NIST FIPS, largely providing guidance regarding cryptography. Much longer is the list of Special Publications, more than 120 including appendices and revisions.

FIPS requirements are mandatory, whereas the Special Publications are more granular guidelines providing practical "how-to" advice on computer security. A handful of the NIST guidance publications cover remedies regarding malware or forensics, but only one, Special Publication 800-61: Computer Security Incident Handling Guide, tackles the issue of how an agency should respond to a major computer

Table 10.1 Assignment of Information Security Responsibilities under Circular A-130

AGENCY

Department of Commerce

Department of Defense

Department of Justice

General Services Administration

Office of Personnel Management

\section{RESPONSIBILITY}

Develop and issue standards guidance

Provide computer security awareness

Offer security planning guidance

Coordinate agency incident response

Evaluate new information technologies

Provide technical advice and assistance

Evaluate vulnerabilities and emerging technologies

Provide guidance on legal remedies

Coordinate with law enforcement on incidents

Pursue legal action in the wake of security incidents

Provide guidance on security in information technology (IT) acquisition

Facilitate contracting for security products

Provide security services to federal agencies

Update and maintain training for awareness and practice

Source: U.S. Office of Management and Budget, Circular A-130. 
security event. What SP 800-61 covers in detail are the general forms of incident that take place: (1) denial of service, (2) malicious code, (3) unauthorized access, (4) inappropriate usage, and (5) multiple components, acknowledging that lines between incident forms may be blurred. These distinctions, while still largely valid, must evolve with the increased sophistication of attacks that target specific resources or actors by multiple mechanisms. SP 800-61 also offers a four-step cycle for incident response: (1) preparation; (2) detection and analysis; (3) containment, eradication, and recovery; and (4) postincident activity. These steps provide the structure for the current civilian U.S. federal government workflow of incident response as discussed below.

\section{Step 1: Preparation}

The first step involves the drafting of policy and identifying resources for incident response. Preparation typically means maintaining systems with no vulnerabilities, or at least as few as possible. In regard to response after a threat has exploited a vulnerability to produce an incident, this is the component of guidance that suggests the formation of an incident or emergency response team. Also involved in this component are mechanisms to escalate response to an incident as necessary. Everything that might be needed to overcome an incident, from human capital to replacement hardware, is covered by this phase of incident response. The emphasis in preparation is in building the foundation for a rapidly scalable activity involving staff who may not hold intimate knowledge of affected systems. Technical documentation of network information, data formats, system policies, and expected operational baselines are vital in incident response.

\section{Step 2: Detection and Analysis}

Analyzing systems operations to detect incidents emphasizes the capacity to identify departure from the norm in system function. This can be fairly simple to detect, as in the case of a denial of service attack in which many users as well as the system manager(s) observe dysfunction, or quite hard, as when an authorized user spirits away data or a camouflaged Trojan awaits instructions to perform its function. 
Baselines for system function are pivotal in detection. Rules should be established for system function, and when those rules are violated, alarms should sound. As such, this component of incident response has been a heavily technical effort. Networks are guarded by intrusion detection systems, hosted by antivirus software, and so on. The problem is that new incidents are occurring rapidly and the code base on which organizational information systems function needs to constantly evolve.

\section{Step 3: Containment, Eradication, and Recovery}

The third step encompasses the often ugly business of repairing damaged systems and returning them to trouble-free operation. It is both a science and an art. Evidence is typically collected and determining the source of the attack is desirous but not always possible. There can be conflicting needs in closing the door on a vulnerability. Improving the chances of successful prosecution may necessitate collection of additional evidence; however, system operators and other stakeholders may want only for the vulnerability to be mitigated and a return to normal operation.

\section{Step 4: Postincident Activity}

Finally, in the postincident phase, emphasis is placed on learning lessons of what occurred and incorporating those into future IT management decisions. This may include determining the costs incurred and assessing the level of harm to the organization and its systems. Of course, some incidents are easier to put a price tag on than others. An hour of downtime on a revenue-generating website has a different cost than the leak of sensitive or classified reports. This variation goes largely unconsidered in NIST guidance today.

\section{U.S. Computer Emergency Readiness Team (US-CERT)}

Also mentioned in SP 800-61 is the role of the U.S. Computer Emergency Readiness Team (US-CERT), a group within the Department of Homeland Security (DHS). US-CERT is a coordinating body for cybersecurity incident response and awareness for the 
U.S. federal government. It publishes known vulnerabilities and is designated to aid agencies in their response to security incidents; however, its products appear somewhat comparable to other vulnerability reporting from industry, and it is unclear to what degree US-CERT renders assistance beyond the boundaries of DHS. Reporting of activity from US-CERT is thin. The December 2010 activity report is typical of US-CERT's public communications. It documents software security vulnerabilities and widely known e-mail phishing scams but provides no hint of what major response activities it might have engaged in during the period in which WikiLeaks and Stuxnet were front-page news.

But rendering assistance in major incidents is what US-CERT is supposed to do. According to federal law, when a computer security incident is discovered by a federal civilian agency, commonly referred to as a dot-gov entity in federal IT circles, it must be reported to US-CERT. This fulfills a FISMA (2011) requirement for federal agencies on "notifying and consulting with the Federal information security incident center," in the event of a security incident, and stands as the point of exchange when an incident migrates from an agency issue to an item to be addressed by an interagency process. This is where federal guidance becomes more complicated, as is evinced within national-level plans to cope with major cyber incidents.

\section{Constructing National Policy for Cyber Incident Response}

The development of national cyber incident response policy occurring in the civilian agencies of the federal government is largely handled by DHS. In December 2003, Homeland Security Presidential Directive 7 (2011) tasked the department with responsibilities to "maintain an organization to serve as a focal point for the security of cyberspace." DHS responded with the publication of its December 2004 National Response Plan (NRP), which superseded response planning prepared by the Federal Emergency Management Agency (FEMA) during the Clinton Administration. The 2004 NRP (Bush, 2004) included a component addressing response to a major cyber attack, the Cyber Incident Annex. In 2008, the NRP was superseded by the newly enacted National Response Framework; however, as of early 
2011 a successor document to the Cyber Incident Annex has yet to be released.

The 2004 Cyber Incident Annex is a highly compact piece of policy guidance for the federal government. It catalogues the agencies to be involved in cyber incident response, identifies policy authorities, and provides a concept of operations for government regarding a nonmilitary cyber incident. As unclassified, public guidance for the community of responders to a cyber incident, it provides only the barest of instructions regarding which offices in government to contact and when to do so in case of an emergency. Two issues raised in the 2004 Annex remain problematic. First is the limited size of pooled expertise on cyber incident response and the capacity for responders to meet a crisis. The second has to do with coordination with the private sector. As the Annex's authors (Bush, 2004, p. CYB-5) opined, "Cyberspace is largely owned and operated by the private sector; therefore, the authority of the Federal Government to exert control over activities in cyberspace is limited." In the Obama Administration's revisiting of a response plan, these items remain the two most complicated.

\section{Currently Planned Efforts}

As of early 2011, the Obama Administration's National Cyber Incident Response Plan (NCIRP) remains a draft. The plan represents an attempt to build upon the White House's 2009 Cyberspace Policy Review, spearheaded by Melissa Hathaway, which recommended preparation of a "cybersecurity incident response plan." Part of a near-term action plan, the NCIRP was prepared by the DHS to serve as a more concrete set of guidance for the United States to work from in the event of a major cyber incident affecting the information systems of the government. NCIRP differentiates between various levels of risk and response with a set of shelves, the National Cyber Risk Alert Levels (NCRAL) (Table 10.2).

Designed to steer resources and activate communications channels in response to a major cyber event, NCIRP is linked to the updated iteration of the NRP, now dubbed the National Response Framework (NRF) (Department of Homeland Security, 2008). Overseen by the Federal Emergency Management Agency (FEMA), the NRF is a selfdescribed guide to an all-hazard response by the nation and provides 


\begin{tabular}{|c|c|c|c|}
\hline LEVEL & LABEL & DESCRIPTION OF RISK & LEVEL OF RESPONSE \\
\hline 1 & Severe & $\begin{array}{l}\text { Highly disruptive levels of } \\
\text { consequences are } \\
\text { occurring or imminent }\end{array}$ & $\begin{array}{l}\text { Response functions are overwhelmed, and } \\
\text { top-level national executive authorities } \\
\text { and engagements are essential; exercise } \\
\text { of mutual aid agreements and federal/ } \\
\text { nonfederal assistance is essential }\end{array}$ \\
\hline 2 & Substantial & $\begin{array}{l}\text { Observed or imminent } \\
\text { degradation of critical } \\
\text { functions with a } \\
\text { moderate to significant } \\
\text { level of consequences, } \\
\text { possibly coupled with } \\
\text { indicators of higher } \\
\text { levels of consequences } \\
\text { impending }\end{array}$ & $\begin{array}{l}\text { Surged posture becomes indefinitely } \\
\text { necessary, rather than only temporarily; } \\
\text { the Department of Homeland Security } \\
\text { Secretary is engaged, and appropriate } \\
\text { designation of authorities and activation } \\
\text { of federal capabilities such as the Cyber } \\
\text { Unified Coordination Group (UCG) take } \\
\text { place; other similar nonfederal incident } \\
\text { response mechanisms are engaged }\end{array}$ \\
\hline 3 & Elevated & $\begin{array}{l}\text { Early indications of, or } \\
\text { the potential for but no } \\
\text { indicators of, moderate } \\
\text { to severe levels of } \\
\text { consequences }\end{array}$ & $\begin{array}{l}\text { Upward shift in precautionary measures } \\
\text { occurs; responding entities are capable } \\
\text { of managing incidents/events within the } \\
\text { parameters of normal, or slightly } \\
\text { enhanced, operational posture }\end{array}$ \\
\hline 4 & Guarded & $\begin{array}{l}\text { Baseline of risk } \\
\text { acceptance }\end{array}$ & $\begin{array}{l}\text { Baseline operations, regular information } \\
\text { sharing, exercise of processes and } \\
\text { procedures, reporting and mitigation } \\
\text { strategy continue without undue } \\
\text { disruption or resource allocation }\end{array}$ \\
\hline
\end{tabular}

Source: National Cyber Incident Response Plan, Interim Version (NCIRP), Department of Homeland Security, September 2010, p. 3.

guidance on how the different layers of government, from federal to local, as well as nongovernmental organizations (NGOs) and the private sector should respond to disaster events.

Largely predicated to serve as the blueprint for an enormous cyber event that has yet to take place, the self-declared purpose of NCIRP is to provide a comprehensive "strategic framework for operational roles, responsibilities, and actions to prepare for, respond to, and begin to coordinate recovery from a cyber incident” (p. 1). NCIRP is important as it is a national plan, not merely one to cover the agencies of the U.S. federal government. Specifically, NCIRP's framework covers all levels of government, from international to local, as well as purveyors and users of IT in the private sector. The document covers four components: (1) a national concept of operations, (2) the organization of the National Cybersecurity and Communications Integration Center, (3) 
an outline of the incident response cycle, and (4) the roles and responsibilities that cut across federal agencies and other stakeholders in the national cybersecurity enterprise. Each component will be reviewed in turn.

\section{Concept of Operations}

According to NCIRP (2010), successful response to a cyber incident depends on effective communication and "requires close coordination across traditional boundaries and requires the development of a robust common operational picture as a foundational element" (p. 3). There is a concern for incident response in regard to communication of information from classified resources inside government and proprietary information held by industry. What the NCIRP will depend upon is a capacity for centralized coordination and decentralized execution. Through its National Cybersecurity and Communications Integration Center (NCCIC), DHS will serve as a hub for response but will need to marshal resources from the Executive Office of the President; Departments of Defense, Justice and State; other Sector Specific Agencies (i.e., Department of Energy for electricity issues); state, local, tribal, and territorial governments, the private sector; and NGOs. In practice this likely means that personnel (analysts, engineers, forensics experts, and others) will be seconded to the NCCIC to cope with a crisis. There may, however, be an issue with such a strategy if many of the stakeholders are also responding to the same crisis.

With the number of participants large in an NCIRP response, the federal government is placed in a position where it should accept that there will be an enormous capacity for leadership discretion in the improvisation of those charged with managing it. Further, according to NCIRP, "The authorities and capabilities of each entity often must change in size, scope and complexity as situations evolve." In the concept of operations, DHS is identified in two capacities, as a supported organization, a role in which it would serve as the lead civilian agency for incident response, and as a supporting organization. In regard to the latter, in a major incident response, lead agency authority may shift to the DoD, but until then, DHS's coordinating bodies would hold the role of shaping incident response. Finally, NCIRP 
acknowledges that, "As incidents become more complex, incorporating cyber and physical effects, more agencies and organizations may need to become involved" (p. 10).

\section{The Response Center}

At the heart of any cyber incident response is the National Cybersecurity and Communications Integration Center. Designed to tackle both day-to-day activities as well as manage more significant incident responses, the NCCIC will be the nerve center of civilian response to major cybersecurity incidents. An amalgamation of the U.S. Computer Emergency Readiness Team (US-CERT), National Coordinating Center for Telecommunications (NCC), and the National Cybersecurity Center (NCSC), the NCCIC also includes input from DHS's Intelligence and Analysis office and, "private sector partners," according to a 2009 press release from DHS. Ostensibly what this input adds up to is large quantities of information regarding security incidents and potential options for response. In mandate, NCCIC is to produce guidance for consumers across government and provide information publicly to those concerned with cyber incident response. This translates to the provision of guidance on security vulnerabilities similar to that provided by industry players such as Symantec and McAfee.

Among the issues of concern for the NCCIC is the capacity to scale up to meet the demand of coordinating the diverse set of actors involved in incident response. Just as the Pentagon grappled with all manner of interservice communications and organizational issues as it pushed the military toward a concept of "jointness" in its operations, so too will there be a need to cover these problems among the set of stakeholders, both public and private, that will be charged with responding to a major cyber event. What DHS will need to consider is how it will create a shared information picture with the command centers of other organizations. For instance, how can the NCCIC develop the capacity to see the situation in network operations centers such as Verizon's in Virginia or AT\&T's in New Jersey when such a need arises? Codifying such relationships will not be easy, but will be necessary so that bonds of trust between U.S. government officials and professionals in the telecom sector will exist when something goes wrong. 


\section{The Response Cycle}

One item given great consideration in the period between publication of the 2004 Cyber Incident Annex and the drafting of NCIRP is demarcating the phases of incident response. In NCIRP, the response cycle is broken down into five phases: (1) prevent and protect (i.e., ordinary day-to-day monitoring and operations), (2) detect, (3) analyze, (4) respond, and (5) resolve. The first two components of the cycle will fall upon the distributed constellation of system owners who may call upon the NCCIC for assistance, but it is the analysis and response portions that will need the greatest degree of attention from DHS and other government stakeholders as the United States moves forward in developing its civilian cybersecurity operations.

In the analysis phase, responders are to identify the incident in its National Cyber Risk Alert Level (NCRAL) system, which is employed to assess the impact of any cyber incident (see Table 10.2). Guidance on responses to be undertaken in responding to and resolving the incident would be based on this four-tiered system. Although the NCCIC will be able to call upon many sources of data regarding threats and vulnerabilities, it would be useful for it to develop strong capabilities in locating expertise and technical talent that can reinforce government efforts in determining the nature of cyber incidents and understanding their impact. Only by having preexisting relationships with the builders of hardware and software, as well as those experienced in mitigating vulnerability with respect to systems of high importance will the analysis portion of the NCIRP's response cycle have the opportunity to meet problems with any chance of success. In the analytical phase, the DHS will need brainpower on tap, and lots of it.

Once the analytical work begins leading to hypotheses regarding remedies, the other great challenge of cyber incident response, mentioned in the 2004 Cyber Incident Annex, emerges, the organization, management, and coordination of surge capacity to mount the response. There is language regarding what parts of an incident action plan to employ in NCIRP, but the extent of reach beyond the boundaries of the federal government envisaged by the NCIRP is unclear. 


\section{Roles and Responsibilities}

Finally, NCIRP (2010, p. 27) specifies some universal roles and responsibilities regarding preparedness, incident response, and recovery. "All organizations are responsible...for preparedness activities," according to NCRIP, including engagement with NCCIC, maintenance of response plans, development of incident assignments, prepositioning of resources, training of incident responders, conduct of response exercises, and institution of evaluation mechanisms. Mandating such activity is an issue not yet decided by the U.S. Congress.

\section{Ways Forward}

Crises are crises because they are largely unexpected or do not conform to advanced planning. As a society, we are increasingly cognizant of problems produced by data breaches and the increasingly realized potential of attacks launched against real pieces of infrastructure controlled by computers. Cyber warfare, which to most seemed like science fiction not long ago, now appears real. Reports of the Stuxnet worm's impact on uranium enrichment activities by Iran and the releases of sensitive information by WikiLeaks are indicators that cyber incident response policy is needed.

A key challenge in the analytical phase, however, is sharing information, both within government and beyond. Pooling together resources to mount an effective response to a national-level incident will most likely involve questioning assumptions on how government and industry work together. For instance, most of the DHS incident responders hold U.S. government security clearances but few in the private sector do. In fact, many of those charged with running and securing the networks of the largest U.S. corporations may not even be residents of the United States.

Furthermore, the universal roles and responsibilities specified in NCIRP speak for a common situational awareness across government and the private sector, but it is unclear this can be mandated. While debate in Congress has often degenerated to disagreement regarding an Internet "kill switch," we are left to wonder how the country will marshal its resources, from the analytical talent found in universities, government labs, and industry to the 
legions of systems engineers that will be needed to clean up the mess that may be a major cyber incident. We have no concept of what civil defense, indeed civil security, means in cyberspace. This must change, and soon.

Then there is the fissure between civil security and military action. The Department of Defense, which has indicated tremendous interest in the topic of cybersecurity and cyber warfare, has yet to release an unclassified doctrine of either offensive or defensive cyber operations. But the United States needs a strong cyber warfare doctrine, according to a former NSA director as reported in Defense Systems (Jackson, 2010), an industry publication, which would be incredibly useful as it usually sets clear rules of conduct and behavior in an organizational setting. Well-crafted, cogent, and adaptive doctrine may allow those on the receiving end of cyber attacks to have a clear idea of who and where to call when a particular piece of evidence is found or type of attack is underway.

But there is the lingering question of when to call in the Pentagon. It will certainly hold significant resources for incident response, but we need to determine the point at which we want the U.S. Cyber Command to collaborate actively with the private sector, such as major Wall Street banks like Wells Fargo, JP Morgan Chase, or the Bank of America. Even though it would be useful to improve information sharing on an ongoing basis regarding incident response between the private and public sectors, this blurs the civil-military lines that will likely prompt strong reactions from corporate and national security lawyers alike, but is necessary nonetheless.

Collaboration on information security matters between government, industry, and academia largely currently rests with working groups constituted under the auspices of the Departments of Homeland Security and Defense, as well as the National Institute for Standards and Technology. These working groups, while helpful in developing relationships and providing venues for discussion are only a piece of the puzzle of developing the capacity to build government/ nongovernment response communities. A better answer may be to constitute regional cybersecurity information clearinghouses in which government is an active participant and does not hold participants at arm's length with onerous national security information control 
regimes. The idea is to have practitioners together to share ideas and expertise both physically and virtually in advance of a major event.

Developing the planning for and actually responding to the cyber incidents that grow in number and impact with each passing month will be the best path to being more effective responders. It is incumbent upon those charged with responding to these incidents to take good notes and share them widely.

\section{References}

Bell, D. E., and L. J. LaPadula, "Secure Computer Systems: Mathematical Foundations," MITRE, 1973.

Bush, G. W., National Response Plan, Cyber Incident Annex, 2004, p. CYB-5. Conklin, W. A., "Why FISMA Falls Short: The Need for Security Metrics," WISP 2008, Montreal, Canada, December 7-9, 2007.

Cyberspace Policy Review, http://www.whitehouse.gov/assets/documents/ Cyberspace_Policy_Review_final.pdf, p. vi.

Davis, J., Memorandum: Suspension of Certification and Accreditation Activity, National Aeronautics and Space Administration, May 18, 2010.

Department of Homeland Security, National Response Framework, January 2008, http://www.fema.gov/pdf/emergency/nrf/nrf-core.pdf (accessed February 9,2011), p. 1.

Department of Homeland Security (DHS), "Secretary Napolitano Opens New National Cybersecurity and Communications Integration Center," http://www.dhs.gov/ynews/releases/pr_1256914923094.shtm (accessed December 3, 2010).

Department of Homeland Security, US-CERT Monthly Activity Summary, December 2010, http://www.us-cert.gov/press_room/monthlysummary 201012.pdf (accessed February 7, 2011).

Department of Homeland Security, Homeland Security Presidential Directive 7: Critical Infrastructure Identification, Prioritization, and Protection, http:// www.dhs.gov/xabout/laws/gc_1214597989952.shtm (accessed December 6, 2010).

Federal IT Dashboard, http://it.usaspending.gov/?q=content/current-yearfy2010-enacted (accessed September 8, 2010).

FISMA U.S. Code - Title 44, Chapter 35, Subchapter III, Sec. 3544, obtained online at http://www.law.cornell.edu/uscode/usc_sec_44_00003544---000-.html (accessed October 28, 2011).

Gates, R., Department of Defense, Fiscal Year 2011 IT President's Budget Request, Department of Defense: Washington, DC, March 2010, https:// snap.pae.osd.mil/snapit/ReportOpen.aspx?SysID=PB2011_NSA (accessed July 27, 2010). 
Homeland Security Presidential Directive (HSPD) Bush, G.W., Homeland Security Presidential Directive 7, Washington, D.C.: The White House, December 17, 2003, from the Federation of American Scientists' Intelligence Resource Program, http://www.fas.org/irp/offdocs/nspd/ hspd-7.html. accessed October 28, 2011.

Hoover, J. N., "NSA Ready To Spend \$902 Million on Informance Assurance," Information Week Security Dark Reading, April 14, 2010, http://darkreading.com/security/government/showArticle.jhtml?articleID=224400245 (accessed July 27, 2010).

Jackson, W. "U.S. needs strong cyberwarfare doctrine, says former NSA director," Defense Systems, July 30, 2010.

Lynn, W. J., "Defending a New Domain," Foreign Affairs, September/October 2010.

National Cyber Incident Response Plan-Interim Version (NCIRP), Department of Homeland Security, September 2010, p. 3.

Neumann, P. G., R. S. Boyer, R. J. Feiertag, K. N. Levitt, and L. Robinson, "A Provably Secure Operating System; The System, Its Applications, and Proofs." SRI International, Menlo Park, CA, February 1977.

Obama, B., Budget of the United States Government, Fiscal Year 2011, Office of Management and Budget: Washington, DC, February 1, 2010.

Ponemon Institute. 2009. Cyber Security Mega Trends: Study of IT leaders in the U.S. federal government.

Verizon 2010 Data Breach Investigations Report. 